\title{
Study on the Artistic Heritage of Kafka form Haruki Murakami's "Kafka"
}

\author{
Li Yang ${ }^{1, a}$, Chen Ting ${ }^{1, b}$ \\ ${ }^{1}$ Hubei Vocational College of Land Resources, Wuhan 430090, China; \\ abjmdngs@163.com
}

Keywords: "Kafka", Haruki Murakami, Kafka, Art heritage.

\begin{abstract}
Haruki Murakami is one of the most influential writers of modern Japan and the world literature, Kafka was the most influential expressionist masters in the twentieth century. Haruki Murakami's masterpiece "Kafka" with distinctive artistic features of Kafka, This paper attempts to study on this viewpoint, discuss Kafkaesk artistic heritage exhibit in "Kafka" from four aspects of surreal grotesque, absurd under real, ubiquitous symbol and strong subjective color.
\end{abstract}

\section{Introduction}

Haruki Murakami, Japan famous modern novelist, is the most influential writer on modern Japan and the literary world. No matter Murakami himself or his works are very attractive, attracted countless readers, critics, psychologists, philosophers and social researchers. In 2002, Haruki Murakami's novel "Kafka" come out, which he named Kafka for the hero, This makes Murakami has reputation of "Japan's Kafka" in the literary in Europe. In early 2006, Haruki Murakami won the "Franz •Kafka" award which was called "Nobel Prize for Literature Prelude" by virtue of "Kafka", then it has become a hot candidate for the Nobel Prize for Literature. In an interview, Murakami expressed his great admiration for Franz • Kafka, Murakami said: "I think what Kafka gives us is his description of the nightmare in his creation. During his life in this world, real life and nightmare somewhat tightly tied together. "'Kafka successfully convey the true horror nightmare implies, not by centralized describe the reaction of the hero, but the nightmare itself nuanced portrayal. " Kafka is the twentieth century's most influential expressionist masters, he accepted the existential theory in ideological terms, performed the person's fear of loneliness and alienation and absurdity of the world theme, reflected the mood at the end of the century. In Haruki Murakami's masterpiece "Kafka" ,there are distinctive artistic features of Kafka, This paper attempts to study on this viewpoint, discuss Kafkaesk artistic heritage exhibit in "Kafka" from four aspects of surreal grotesque, absurd under real, ubiquitous symbol and strong subjective color.

\section{surreal grotesque}

Grotesque is an extremely important expression of literary trends in the 20th century, Kafka's works often show grotesque state, it is often unreasonable whether from shaping the character or storyline arrangement, it is an abstract story which embodies alienation and strangeness in the whole world. In the comic-style story, society as a lifeless machine has a strong color of fable. At the same time many of Murakami's works such as "Hard-Boiled Wonderland and the End of the World", "odd shape birds recorded", "A Wild Sheep Chase" has absurd plot, illogical time and space, a lot of metaphors and symbols gave readers a new shock. 
Story frame of Haruki Murakami's novel is often surreal, takes double clue narrative strategy. One side is the world of illusory consciousness, the other side is the real world of the senses. The Following is the works of the absurd imagery, specifically in abstract imagery and strange feeling. In "Kafka", there are also many weird things: cats speak human language, fish from heaven, collective amnesia, flexible interpretation of the article makes people dumbfounded and finally the white monster climbed out from the mouth Tanaka, it has no meat, no bones, no organs and no brains, knifed not to death, beat not bad, wound would be restitution when pulling out the knife, monster still climbed out, as if that nothing had happened.

"Kafka" is constituted by the two clues which are reality and fiction, from the view unreal trail, even chapter said during the war, a female teacher lead children to the mountain to take mushrooms, but encountered a strange collective insomnia accident. After that, the children regained consciousness one by one, without any strange of the body only lost the memory coma before. Unfortunately, a boy evacuated from Tokyo named Nakata has not returned to normal, he lost the ability to read and write, forgot relatives and his name, became downright shell, zombie to live much of his life. Similar to the exchange, Nakata gained the ability to communicate with a cat and the outside world can be displayed miracle according to his will. In the sixth chapter, there is a "cat and person dialogue." This section occupies a lot of space in the whole text. In the text, as humans, Nakata's intelligence is inadequate, but as the cat it warned and helped Nakata with a wise gesture. We will unconsciously associate to the well-known Japanese writer Natsume Soseki's classic work "I am a cat." Text reveal that modern violence is everywhere vaguely, sounded the alarm for the emergence of our modern human civilization crisis.

\section{Absurd under real}

Absurd is the most significant feature of Kafka's novel, text tried to portray the essence of life that is conflict between absurd in real world and people trying to get everything reasonable. Novelist use of this absurd artistic effectively also because of his insight into the truth after absurdity. Kafka's works are usually exudes magical qualities of fantasy and reality, the inevitable and chance fate, persistent and anxiety, despair and redemption, cowardice and tenacious, introspection and impulse. The profound absurdity demonstrated in work is art's authenticity from another point of view. These seemingly absurd phenomena revealed the nature of the relationship between people and the unknown of world more deeply. The same artistic charm also demonstrated in the many works of Haruki Murakami, especially in "Kafka".

Absurdity first performance on the style of his work, he often uses narrative mode to parallel development with two clues. Formatted two characters' space which are "outsider" and "reality", "this side and the other side", "end of the world and cold in Wonderland", "inlet and outlet", complement each other. These works give people ridiculous, elusive feeling in the plot and structure mostly, while the details of the story is specific, vivid and convincing, especially the emotional character shape in the space of heterogeneity, it reflects people's psychological state. Specifically, "Kafka" presented above characteristics vividly in the search for the meaning of existence, story structure set and theme built. The text Merged virtual clue and real clue, which is a rebellion and innovation to traditional Japanese literature structure, and also gave his literary works a "Murakami mark."

One of the main plot of the novel is that Kafka walking alone in the park when he suddenly collapsed and loss of memory, he woke up only to find himself covered with blood. What is even more strange that his father was killed at the same time in the faraway Tokyo. But Nakata who killed Qiongniwoke who is a kitten mad lost his conscious without any blood. These bring us many 
doubts. These unconscious behavior seems absurd in the text, but it is real side of human . In the text, there lack of understanding and trust between the family, everyone living in the deep solitude. Absurd in this text is the accurate grasp of whole real world by the writer, when he tried to show the absurdity, truth would appear. It would appear that with the fantastic story can be more accessible to the essence of things. Murakami's work has a very strong magical color, this absurd and true mutual integration exudes a charm that is real and imaginary.

\section{Ubiquitous symbol}

Symbols and metaphors are means of expression often used in modern literature in twentieth century, Kafka generally communicate his perception of social relationships with symbolism. He is also good at the use of symbolism. In the beginning of "Kafka", hero Kafka obeyed a teenager called crow. Obviously the teenager called crow is a symbolic presence, it is a prophet of fifteen years old boy, is illusion of loneliness and emptiness. The characters get throughout the story, alluding Saeki's dead lover Kafka in the later chapter. It is worth mentioning that the name of the work "Kafka" is coincided with the a painting and a song in the text. The content of painting is a boy looking at the distance by the sea, alone and very sad, like a existence of mystery. The song was made by Saiki when he was a teenager, the content is rather obscure and full of hints and symbolic.

Imagery is a basic units when expressing symbol. Turning to the images in the text, the well, the forest, the mirror appears most frequently. Murakami's works generally exhibit binary oppositions space and structure, these images tend to become a third space connected to reality and outside. For the edge of the forest, Kafka Tamura feared in the beginning nostalgia in the end. It reflects the utopian nature of the forest zone has a spiritual healing function. Forest eventually became the integral and important part of spiritual world for teenage Kafka, this also shows the author's own inner world of self-awareness. According to Frye's criticism prototype, prototyping can be imagery, symbolism, themes, plots, characters or structural unit, as long as they appear repeatedly in the works.

juvenile Kafka was abandoned by his mother, cursed by his father repeatedly and predicted that he would kill his father and intercourse with his sister and mother. He hates and is afraid of his father, but more afraid of that terrible prophecy. So he made himself strong silently, then escape from Tokyo to the four countries where without known people. He settled in a village memorial library in chance, Kafka had a relationship with Saiki and cherry successively in a dream, one looks like his mother and the other one was like his sister. Juvenile Kafka was like Oedipus in the ancient Greek myth, as if all the efforts made had failed and ultimately could not escape the tragic fate. In the even-numbered sections of "Kafka", Nakata lost his life because of his teacher's violence during world war II, he turned into an empty shell. When he died, there was a white beast climbed out from his mouth, this implies a continuation of violence in the history. Qiongniwoke abused cats, the elder man killed Qiongniwoke, Juvenile Kafka patricide Etc. modern violence is everywhere. Everyone no matter children or adults are burdened with deep loneliness and sadness. Therefore, the author took shadow of World War II in Japan as background, used the method of symbolism, reflected the social life and psychological state after the war through bold bizarre plot, rethinking national culture standing ethnic angle.

\section{Strong subjective color}

The creative process of art is the expression of the inner world, but Kafka usually do not directly 
express his views in his works. He usually portrayed external shocks of inner visions, emphatically convey his metaphysical spiritual experience, explored and organized his subconscious and intuitive moment. In Kafka's novels each story is an absurd dream, which is logical confusion, unreasonable. It has a closed connection with his view of world. he tends to absorb the local scene in the real world to his heart, converses it into a real art after much thought and unique processing, artistic then bring it to the real world outside, finally, becomes "corresponds to the world" reflecting the inner world. The outside world Kafka can see is derived from his inner needs, thus the real world in his eyes filled with a strong subjective color.

Haruki Murakami said in the preamble of "Kafka", "Kafka Tamura contract it down as a story using an extreme form from our actual experience of fifteen years old. The text depict a world though a fifteen juvenile eyes, Kafka Tamura is my own and also is your own. " This is also where the author's intention, is the meaning of existence for this text. Kafka has a meaning of "The Raven" in Japanese, coincided with the "a teenager named crow" repeatedly in the text, this suggests that they are one person. As can be seen from the text, " a teenager named crow " is illusory existence, is a part of Kafka Tamura. Murakami took writing as a self-healing manner, after writing he could get a hint of relief of sprit, that is "when you wake up, you will become a part of the new world." the new end, new self. The hero said the whole world with a new vision, himself had taken place profound changes. In certain point of view, the hero completed the transformation, to look at external things in a new view.

For Murakami, the creative process of literature is his continuous exploration process of himself, is a journey within himself, he explores his subconscious and determines its meaning. "Forest, well, hole," is images Murakami often used, suggesting that his own internal world, the world has a maternal tolerant, heal various wounds of hero. Murakami’s novels mostly emerged: Lost - Looking for - lost. The hero often escaped from reality at first, then got some kind of revelation from outside, after the liberation of the soul, returned to reality with a new attitude. The meaning of finding process is extraordinary for entire life course. Murakami said before: Anyone in your lifetime are all looking for a precious thing, but not many people can find it, even if he was fortunate and found it, in fact, what he found was fatally damaged in many cases. Even so, we still continue to look for it. If not, the meaning of life would not exist.

\section{Summary}

Kafka as an expressionist master, depicts human's loneliness and fear of the next century with his Touch with his sensitive dedication, it's precise and rich content, so we have unlimited possibilities of elucidation. And Haruki Murakami, as a post-modernist writer, understood Kafka, connected with the reality of Japanese society at the same time, gave contemporary significance of the violence and loneliness theme, demonstrated his unparalleled imagination. Through the study of the artistic heritage of Haruki Murakami's novel "Kafka", we have a more comprehensive and profound understanding to Murakami's works, it is difficult to determine if we are reading Kafka or Haruki Murakami if there is no description of Japan streets, landscapes and customs in Haruki Murakami’s work. With the reputation of "Japan's Kafka", Haruki Murakami is welcomed by readers in the last decades, he uses the classic "Kafkaesque" style, depicts the emotional contradiction in the city. Haruki Murakami and Kafka create the grotesque world which is independent of the real one, to reflect on contemporary society with their own unique perspective, character spiritual emptiness and nothingness. When the substance is expanding, but the human's soul has not kept pace, they are all struggling to find a way out.From the 19th century to the early 20th century, Kafka in Austria tried to explore the mysteries of human nature. By the 21st century, Haruki Murakami at the east of 
Japan helps readers rediscover themselves, understand the social with the power of words again in the view of Kafka with his independent attitude.

\section{References}

[1] Dong Debu, Comments on "Kafka" from the perspective of text analysis, J. Admire masterpieces. 18 (2014).

[2] Xiang Bixiao, "Kafka" shadow in the works of Haruki Murakami, J. Youth and Society. 8 (2013).

[3] Wu Sijia, On "Kafka" Themes, J. Southwest Agricultural University (Social Science Edition). 7 (2011).

[4] Su Ping, Modernism and postmodernism blend - artistic analysis of Haruki Murakami's "Kafka", J. Japanese Study and Research. 1 (2011).

[5] Cao Lin, Shuttling between reality and fantasy - Look for the Creative Features from the "Kafka" by Haruki Murakami, J. Theory. 14 (2010).

[6] Zeng Yanbing, Kafka and Prague Kafka, J. Admire masterpieces. 9 (2010).

[7] Lin Miaodan, To see the similarities and differences between Kafka and Haruki Murakami from "Kafka", J. Leshan Teachers College. 8 (2010).

[8] Zhu Daowei, Haruki Murakami Review on Chinese Mainland, J. Yangtze University (Social Science Edition). 16 (2008).

[9] Li Chong, Reading Haruki Murakami "Kafka", J. CULTURE. 34 (2007).

[10]Wei Dahai, Haruki Murakami novel heterogeneous characteristics - Understanding of "Kafka", J. Foreign Literature Review. 3 (2005). 